\title{
Natal Luz de Gramado: um patrimônio cultural da comunidade promovendo desenvolvimento regional na Serra Gaúcha
}

\author{
Daniel Luciano Gevehr \\ Programa de Pós-Graduação em Desenvolvimento Regional das Faculdades Integradas de Taquara (Faccat) \\ Roger Pierre Vidal \\ Mestrando do Programa de Pós-Graduação em Desenvolvimento Regional das Faculdades Integradas de Taquara \\ (Faccat) \\ Aline Nandi \\ Mestranda do Programa de Pós-Graduação em Desenvolvimento Regional das Faculdades Integradas de Taquara
}

(Faccat)

\begin{abstract}
Resumo
O presente trabalho apresenta uma revisão conceitual sobre o "Natal Luz" de Gramado, evento que desde 2008 transformou-se em Patrimônio Cultural do Estado do Rio Grande do Sul, assim definido pela Lei $\mathrm{N}^{\circ}$ 13.060. A preocupação central do artigo é percorrer a trajetória do evento, desde seu surgimento em 1986 até o ano de 2013, analisando os diversos impactos da globalização sobre este Patrimônio Cultural do Estado do Rio Grande do Sul. Fundamentamos a análise exploratório-descritiva sobre este que se tornou o maior evento de Natal da América Latina, realizado na cidade de Gramado, descrevendo seu processo de transformação em patrimônio cultural. Para tanto, foram realizadas pesquisas bibliográficas e documentais que fundamentaram a problematização da pesquisa. Buscamos, com isso, compreender os impactos da indústria do turismo na evolução e transformação deste patrimônio local, vivenciado e construído pela comunidade, em um patrimônio agora conhecido internacionalmente.
\end{abstract}

Palavras-chave | Desenvolvimento regional; globalização; indústria do turismo; Natal Luz de Gramado; patrimônio cultural.

Código JEL | L83; O18; R11. 


\title{
CHRISTMAS OF LIGHT IN GRAMADO: A COMMUNITY CULTURAL HERITAGE PROMOTING REGIONAL DEVELOPMENT IN THE SERRA GAÚCHA
}

\begin{abstract}
In this study we present a conceptual revision on the event known as Natal Luz (Christmas of Light), hosted in the city of Gramado - RS. It has been officially considered part of the state of Rio Grande do Sul's cultural heritage since 2008, as defined by the Law number 13.060. The aim is to analyze the event from its beginning until the present time, that is, from 1986 to 2013. We wished to take under consideration the impacts of globalization on the cultural heritage of Rio Grande do Sul. Our study, which is exploratory-descriptive, is based on the greatest Christmasrelated event in Latin America, by describing its formation process into its condition of cultural heritage. So we established the research problem overall through bibliographical and documental research. By employing this approach we have sought to understand the impacts of the tourism industry on the evolution of this local heritage, which was built and is currently lived by the whole community as an event known worldwide.
\end{abstract}

Keywords | Christmas of Light in Gramado; cultural heritage; globalization; regional development; tourism industry.

JEL-Code | L83; O18; R11.

\section{NAVIDAD LUZ DE GRAMADO: UN PATRIMONIO CULTURAL DE LA COMUNIDAD PROMOVIENDO DESARROLLO REGIONAL EN LA SERRA GAÚCHA}

\section{Resumen}

El presente trabajo presenta una revisión conceptual sobre la "Navidad Luz" de Gramado, evento que desde 2008 se transformó en Patrimonio Cultural del Estado de Rio Grande do Sul, definido en la ley $\mathrm{N}^{\circ}$ 13.060. La preocupación central del artículo es recorrer la trayectoria del evento, desde su surgimiento en 1986 hasta el año de 2013, analizando los diversos impactos de la globalización sobre este patrimonio cultural. Se trata de un análisis exploratorio sobre éste que se tornó el mayor evento de Navidad de América Latina que describe el proceso de transformación en patrimonio cultural. Para esto, fue realizada una investigación bibliográfica y documental que dieron fundamento a la problematización de la investigación. Con esto se buscó comprender los impactos de la industria de turismo en la evolución y transformación de este patrimonio local, vivenciado y construido por la comunidad, en un patrimonio internacionalmente conocido.

Palabras-clave | Desarrollo regional; globalización; industria de turismo; Navidad Luz de Gramado; patrimonio cultural.

Código JEL | L83; O18; R11.

\section{Introdução}

O Natal Luz de Gramado, tomado como Patrimônio Cultural, nos remete ao processo de construção e difusão da identidade cultural de Gramado (RS), ou seja, 
nos leva a pensar sobre o processo que envolve a formação histórica e cultural dessa comunidade. A Lei n 13.060 do ano 2008, que torna o evento o Natal Luz um Patrimônio Cultural do Estado do Rio Grande do Sul, contribuiu para o revigoramento da memória do principal evento turístico da Serra Gaúcha e também para o fortalecimento, no imaginário do turista, quanto à imagem do Natal Luz.

Esse evento se coloca atualmente como um instrumento de legitimidade e de identidade da cidade de Gramado, na medida em que as representações presentes no evento se apresentam como fatores de perpetuação de determinadas memórias, as quais procuram evidenciar a cidade como um "espaço de alegria e felicidade", associado à data do Natal, celebrada em dezembro. Observamos que o evento desempenha, ainda, um importante papel social, na medida em que se propõe a transmitir e preservar a identidade da sociedade gramadense. Nessa perspectiva, podemos citar Rodrigues (2006), quando afirma que a identidade é um processo de interação, o qual os indivíduos experimentam em sua realidade, que em nosso caso, é Gramado.

Para melhor compreendermos as relações que se estabelecem nesse espaço de construção das atividades que constituem o Natal Luz de Gramado, nos valemos dos estudos realizados pelo antropólogo Joël Candau, para quem a identidade é "uma construção social, de certa maneira sempre acontecendo no quadro de uma relação dialógica com o Outro.” (CANDAU, 2012, p. 9). Nessa mesma linha, o autor afirma que a memória - elemento indispensável da construção da identidade de uma comunidade - é "uma construção continuamente atualizada do passado, mais do que uma construção fiel do mesmo.” (CANDAU, 2012, p. 9).

De acordo com o antropólogo, a memória atua diretamente no processo de fabricação das identidades, na medida em que ela acaba definindo aquilo que se quer ou não lembrar e representar para os outros. Assim, um evento como o Natal Luz é entendido como um fenômeno social no qual o passado da comunidade é redefinido de acordo com os interesses do presente, que, nesse caso, nos parecem estar associados essencialmente às questões econômicas.

Assim, a identidade gramadense, alicerçada no princípio da valorização do trabalho, herdado dos imigrantes alemães e italianos que ocuparam a região no século XIX, se torna um elemento fundamental de representação social, na medida em que esses valores são de fato o que se quer mostrar para os outros. Entretanto, vale ressaltar que não observamos em Gramado elementos étnicos associados à imigração alemã ou italiana sendo explorados nas atividades do Natal Luz, até mesmo porque defini-los de forma clara seria uma tarefa bastante complexa.

Sobre essa questão, Poutignat e Streiff-Fenart afirmam que "a primeira ingenuidade é acreditar que se pode definir uma unidade étnica (quaisquer que sejam os critérios utilizados para defini-la) por uma lista de traços." 
(POUTIGNAT; STREIFF-FENART, 1998, p. 61) Em seguida, os autores, valendo-se dos estudos clássicos de Frederik Barth, afirmam que "Barth e seus colaboradores demonstram ser impossível encontrar um conjunto total de traços culturais que permitam a distinção entre um grupo e outro, e que a variação cultural não permite por si própria abranger o traçado dos limites étnicos." (POUTIGNAT; STREIFF-FENART, 1998, p. 61).

Dessa forma, os traços identitários que identificam a comunidade ao espaço da cidade se tornam ainda mais visíveis quando observamos a preocupação da municipalidade em preservar o centro da cidade limpo, com canteiros floridos, e a proibição da circulação de mendigos nas proximidades da avenida principal da cidade, que é a Avenida Borges de Medeiros - que para muitos moradores e turistas é a avenida que melhor "representa" Gramado. Nesse caso, a boa aparência da cidade é compreendida pelos grupos dirigentes da comunidade como um elemento físico mas ao mesmo tempo simbólico - de desenvolvimento e potencialização do Turismo na cidade e na Região das Hortênsias.

Retomando as ideias defendidas por Candau, que por sua vez se vale das pesquisas de Marc Guillaume, vemos que o patrimônio funciona como um "aparelho ideológico da memória." (CANDAU, 2012, p. 158). Isso se explica em virtude do patrimônio da comunidade ser compreendido como um verdadeiro transmissor da memória do grupo, agregando valores, ideologias e formas de pensar, além é claro, de representar o passado dessa comunidade, que agora encontra-se patrimonializado, como em eventos promovidos pela coletividade. Sobre essa questão, que envolve o patrimônio e sua produção, Candau afirma ainda que "a história do patrimônio é a história da construção do sentido de identidade e, mais particularmente, aquela dos imaginários de autenticidade que inspiram as políticas patrimoniais." (CANDAU, 2012, p. 159).

Entendemos que o Natal Luz de Gramado pode ser compreendido como um exemplo dessa manifestação exposta pelo autor. Gramado patrimonializou o evento alusivo ao Natal e transformou o evento numa festa popular, comunitária, ainda que com o passar do tempo o evento tenha passado por um processo de sofisticação cada vez maior, excluindo parte da população mais humilde da cidade, que passa a não se fazer representada no evento. Com isso, o patrimônio da comunidade passa a representar cada vez mais as "partes" e não o "todo" de uma comunidade, cada vez imersa no processo de mercantilização de seus bens culturais, que originalmente conferiam uma certa identidade de grupo aos seus moradores.

Nesse aspecto, parece que estamos diante de um processo que Candau chamou de "destruição voluntária" (2012, p. 163), no qual comunidades podem fazer desaparecer instrumentos, casas, vestimentas e outros tantos objetos do passado, que mostravam as dificuldades de um tempo que se quer esquecer. A lembrança de Gramado nos tempos da Colônia parece servir, nesse contexto, apenas de 
suporte da memória, para se mostrar o quanto se prosperou e o quanto a cidade se desenvolveu economicamente. Assim, as apresentações de música, os desfiles, os shows de luzes e demais atividades que integram o Natal Luz procuram evidenciar esse progresso da comunidade na atualidade.

Poderiamos ainda pensar essas transformações no cenário gramadense a partir da teoria proposta por Lewis Mumford, importante estudioso do fenômeno urbano e de suas tranformações. Para ele, "a principal função da cidade é converter o poder em forma, a energia em cultura, a matéria inanimada em símblos vivos de arte, a reprodução biológica em criatividade social.” (MUNFORD, 1998, p. 616).

De acordo com o historiador, a cidade passa, obrigatoriamente, por transformações que buscam redimensionar seus atores na medida em que todos procuram se (re)adequar as novas invenções e necessidades que chegam até o espaço da cidade. A partir dessa ideia, percebemos que, no caso de Gramado, a cidade que chegou ao século XXI apresenta novas características, que cada vez mais a distanciam de seu passado imigrante. Esse passado, no entanto, é (re)atualizado, na medida em que observamos uma grande preocupação com a representação do progresso alcançado pelos seus moradores, que superaram as dificuldades e assim "venceram".

Buscando melhor fundamentar nossa análise, buscamos discutir os sistemas classificatórios que envolvem a produção dessas identidades. Katryn Woodward (2014, p. 40) nos ajuda a entender essa questão, afirmando que as identidades são fabricadas através de um processo que envolve a marcação das diferenças, o que, segundo ela, ocorre através de sistemas simbólicos de representação ou por meio da exclusão social. Segundo a autora, a identidade depende diretamente da diferença, na medida em que a diferença simbólica ou social se estabelece por meio de sistemas classificatórios, onde se definem aquilo que é nosso ou dos outros, ou entre aquilo que queremos mostrar e aquilo que queremos esconder.

Assim, a identidade de Gramado passa, obrigatoriamente, por esse processo. Os diferentes grupos sociais que constituem a comunidade passam por um processo classificatório no qual, aqueles grupos que detêm o poder em suas mãos, acabam determinando esse processo de classificação, que consiste basicamente em imprimir uma - e não várias - identidade ao espaço geográfico compreendido como cidade. O evento Natal Luz é uma forma de classificação da identidade local, na medida em que esses grupos elegem aquilo que deve ser valorizado, como no exemplo do Parque Knor, localizado no centro da cidade e onde encontramos a casa do Papai Noel e a neve artificial - ou até mesmo aquilo que deve ser retirado - ou colocado de forma secundária - na pauta de programação do evento.

Aliás, elementos como a Casa do Papai Noel, a neve artificial e a farta decoração natalina espalhada pelas principais ruas, praças e avenidas da cidade são exemplos concretos daquilo que classificamos como hibridismo cultural, no qual elementos de diferentes contextos e épocas aparecem reunidos num mesmo espaço. Assim, o 
hibridismo pode ser compreendido como sendo "a mistura, a conjunção, o intercurso entre diferentes nacionalidades, entre diferentes etnias, entre diferentes raças - coloca em xeque aqueles processos que tendem a conceber as identidades como fundamentalmente separadas, divididas, segregadas." (SILVA, 2014, p. 87). Ainda de acordo com o autor, a identidade que resulta desse processo de conjunção de diferentes elementos não é mais nenhuma das identidades anteriores, embora preserve diferentes traços originais.

Queremos, a partir da perspectiva dos estudos culturais, compreender que a identidade presente no evento Natal Luz de Gramado encontra-se precisamente nesse contexto. Na medida em que o evento traz em sua programação diferentes lugares para visitação, shows de diferentes naturezas, personagens, desfiles festivos no centro da cidade e uma culinária variada, observamos que estamos tratando de bens culturais que não são "naturais da cidade", mas sim importados de diferentes lugares e culturas.

Exemplo disso é o próprio Papai Noel, que foi incorporado ao evento, como personagem secundário, visto que as festividades voltam-se cada vez mais para o consumo de bens e serviços oferecidos pela cidade e seus empresários. Com isso, o Natal Luz passa a ser um evento bíbrido, multicultural, multiétnico e internacionalizado, contando com diferentes elementos que, conjugados no espaço local, passam a dar uma identidade própria ao evento.

Dessa forma, o Natal Luz tem uma identidade própria, ainda que nele se observem diferentes traços originais de outras culturas e lugares, que, reunidos, passam a produzir em Gramado um novo significado, um novo simbolismo, que por sua vez é percebido - e representado - de forma diferente para cada sujeito envolvido no processo, seja ele morador da cidade ou turista.

A partir disso, percebemos que o Natal Luz foi instituido e reconhecido pela comunidade como o maior evento de Natal da América Latina. Ainda que existam diversas críticas a respeito de sua mercatilização, o evento produziu na cidade um processo de identificação com a época do Natal e todas as atividades culturais que ocorrem na cidade em decorrência do Natal Luz.

Nessa perspectiva, consideramos fundamental a análise feita por Stuart Hall, quando esse afirma que a identificação é sempre "um processo de articulação, uma suturação, uma sobredeterminação, e não uma subsunção. Há sempre demasiado ou muito pouco - uma sobredeterminação ou uma falta, mas nunca um ajuste completo, uma totalidade." (HALL, 2014, p. 106). Seguindo sua análise, Hall afirma ainda que "como todas as práticas de significação, ela está sujeita ao jogo da différance." (HALL, 2014, p. 106).

Ou seja, de acordo com o jogo da différance, a comunidade de Gramado acabou incorporando "o jogo", através do qual, praticamente, "todos ganham" com o evento de Natal. Se, por um lado, o evento transformou-se em uma atividade cada vez mais sofisticada e preocupada em atender aos interesses daqueles que detêm a 
riqueza e o poder local, por outro acaba promovendo desenvolvimento - ainda que em menor escala - para a maioria da população da cidade. Isso se observa se considerarmos o aumento de postos de trabalho, aumento de circulação de pessoas na cidade e consequente aumento de prestação de serviços variados, destinados a satisfazer as necessidades e anseios dos turistas, interessados em percorrer os caminhos da cidade e consumir aquilo que é oferecido.

Neste sentido, notamos que se deu na cidade a adoção de uma política de tornar o evento Natal Luz um Patrimônio Cultural protegido através da efetividade das políticas públicas. Nesse sentido, tiveram papel fundamental a administração pública municipal e as principais lideranças ligadas à economia de Gramado. Com isso, o patrimônio imaterial da sociedade local passou por um processo de patrimonialização dos bens culturais, reafirmando a sensação de pertencimento e valorização da comunidade gramadense, podendo assim fomentar o desenvolvimento local. Entretanto, sabemos que se essa ação não for bem orientada, pode ter seu resultado em parte redimensionado: ao invés de favorecer a revitalização dos bens culturais, acabou transformando-os em mercadorias voltadas para o consumo de massa.

Entendemos Gramado, enquanto uma cidade preocupada com o desenvolvimento do Turismo, na acepção dada por José D'Assunção Barros (2007, p. 45), para quem "a cidade também fala aos seus habitantes e aos seus visitantes através dos nomes próprios que ela abriga: dos nomes de ruas, de edifícios, de monumentos. O grande texto urbano aloja dentro de si textos menores [...]." É nesse cenário urbano que encontramos o Natal Luz, com sua dinâmica e organização próprias, vinculada com os lugares da cidade e com as potencialidades turísticas que a mesma permite explorar de forma indissociável à programação do evento natalino. De acordo com o autor, nesse caso, a cidade assume - numa perspectiva marxista - a sua dimensão econômica, permitindo sua "ênfase no consumo como fator central na especificidade citadina." (BARROS, 2007, p. 59).

Intrepretados a partir de diferentes ângulos, Gramado e o Natal Luz podem ser lidos sob diferentes perspectivas que convergem para uma mesma questão, a qual norteia nossa pesquisa: como o Natal Lu₹, enquanto um evento anual realizado pela cidade de Gramado, promove o desenvolvimento da cidade e como sua dinâmica permite construir uma certa identidade cultural para a cidade e seus moradores, através da patrimonialização do evento?

Independente das possibilidades de leitura que esse contexto nos permite realizar, a questão principal que se coloca aqui são as relações possíveis entre o desenvolvimento local e regional, a identidade da comunidade e as (re)atualizações da memória da comunidade, na medida em que ambas inserem-se num mesmo quadro de análise, no qual a patrimonialização dos bens culturais da comunidade são (re)utilizados pera promover o desenvolvimento de Gramado.

Reafirmamos que o objetivo deste artigo é discutir a trajetória do evento Natal Luz até o momento em que esse se torna um patrimônio cultural do estado do Rio 
Grande do Sul e analisar o processo de evolução desse evento em torno da agregação de valor deste bem cultural.

Para tanto, temos como um de nossos objetivos a análise do processo que envolveu a valorização da identificação da história e da cultura da população local, bem como a promoção do desenvolvimento local. Em relação à estas questões, podemos lembrar aquilo que Feitosa e Silva (2011) apresentam - e que de certa forma já apontamos nas páginas anteriores -, ao sustentarem que uma alternativa de patrimonialização pessimista se coloca quando um patrimônio imaterial se transforma em apenas uma mercadoria de consumo visando o lucro econômico, tornando-se, dessa forma, um patrimônio pessimista, que se presta exclusivamente a fins econômicos, sem se preocupar com questões sociais ou culturais ou até mesmo com o processo que envolve a memória coletiva (HALBWACHS, 2004) da comunidade.

\section{O contexto de Gramado, suas origens e o surgimento do Natal Luz}

A cidade de Gramado está localizada na serra gaúcha, estado do Rio Grande do Sul, e fica distante $115 \mathrm{~km}$ da capital do Estado, Porto Alegre. Segundo dados da Fundação de Economia e Estatística do Rio Grande do Sul/FEE (2013), a cidade possuía, no ano de 2010, 32.273 habitantes. Segundo o Censo IBGE 2010, a população urbana de Gramado alcança 29.013 e a população residente na área rural é de 3.260 habitantes.

Gramado tem uma das melhores estruturas do país em termos de hospedagem, contando com o número de 136 hotéis e pousadas, num total de 11 mil leitos, e é uma cidade tipicamente turística. Segundo o Sindicato da Hotelaria, Bares e Similares de Gramado, 43\% do PIB da cidade é proveniente do setor hoteleiro.

A Tabela 1, apresentada abaixo, evidencia a importância do Turismo na economia de Gramado, pois o setor corresponde a 61\% do Valor Adicionado Bruto (VAB) no ano 2008. Percebe-se que a média do VAB de serviços em Gramado é maior que a média do VAB de Agropecuária e Indústria. Isso se deve, principalmente, pelo fato de Gramado possuir sua base econômica atual no setor de Turismo, sendo esta a estrutura predominante no setor de serviços. 
Tabela 1 - Composição do PIB a preços correntes, Gramado, 2005-2008

\begin{tabular}{lrrrr}
\hline \multicolumn{1}{c}{ Setor econômico } & \multicolumn{4}{c}{ Anos bases } \\
& \multicolumn{1}{c}{2005} & \multicolumn{1}{c}{2006} & \multicolumn{1}{c}{2007} & \multicolumn{1}{c}{2008} \\
\hline Valor adicionado bruto da Agropecuária & 9.753 & 11.674 & 8.027 & 9.499 \\
Valor adicionado bruto da Indústria & 82.304 & 88.049 & 105.109 & 112.823 \\
Valor adicionado bruto dos Serviços & 255.847 & 239.050 & 272.732 & 299.481 \\
$\begin{array}{l}\text { Impostos sobre produtos líquidos de } \\
\text { subsídios a preços correntes }\end{array}$ & 49.469 & 53.117 & 57.171 & 68.481 \\
\hline PIB a preços correntes & 397.373 & 391.890 & 443.039 & 490.284 \\
\hline
\end{tabular}

Fonte: IBGE, Contas Regionais do Brasil.

Em 2011, a cidade de Gramado ganhou o prêmio "Melhor Cidade Turística e Melhor Destino de Inverno do Brasil", prêmio este concedido pela Editora Abril S/A, por indicação de uma pesquisa feita com os leitores da revista "Viagem e Turismo".

É importante lembrar que Gramado começou como vila e mais tarde se tornou um distrito, e finalmente um município. O processo da evolução de Gramado passou por características comuns a todos os municípios da Serra Gaúcha. Por ser um lugar de passagem nos séculos XVIII e XIX, os tropeiros tinham a serra como trajetória para chegar aos grandes centros. Por isso, Gramado se formou com traços do turismo - tomadas as devidas proporções de época - desde seus primórdios, sendo desde sua formação um lugar de descanso para os tropeiros que por ela passavam com seu gado, com destino a São Paulo.

Consultando o Gramado Site, encontramos algumas informações sobre o processo de ocupação da cidade, apresentados por Daros (2012), que afirma que ela foi inicialmente povoada pelos alemães e italianos que ali construíram suas comunidades, como a Linha Tapera e a Linha Marcondes.

Assim, ao lembrar do passado luso - anterior à imigração alemã e italiana na região -, a pesquisadora afirma que os tropeiros que passavam pelo lugar tinham esta terra como um lugar de repouso e descanso, com muita "grama verde" e coberto por inúmeras árvores. Daí o lugar ter recebido o nome de Gramado. Destaca-se, ainda, o fato de que os tropeiros abriram os caminhos para a imigração italiana e alemã, sendo que estes imigrantes vislumbravam nas áreas novas uma expectativa melhor de vida e de trabalho em terras pouco exploradas.

No começo do século XX, Gramado recebeu levas significativas de imigrantes italianos e alemães - bem como de descendentes desses imigrantes - que vinham de regiões coloniais próximas, motivados pelo processo de ocupação das terras do estado por meio das doações e venda das sesmarias. Com esse processo de 
povoamento tiveram inicio os primeiros povoados de Gramado. Segundo Daros (2012), os imigrantes provinham de cidades como Caxias do Sul, São Marcos, São Sebastião do Cai, São Leopoldo, Taquara, entre outras.

Com a imigração logo surgiram as primeiras comunidades organizadas de Gramado, chamadas Linhas (denominação para as antigas colônias da época). As Linhas tornam-se organizadas e surgem às primeiras associações, igrejas, clubes, que vão transformar as paisagens da região. Com as trocas culturais, italianos e alemães passam a partilhar o legado cultural das técnicas de trabalho industriais e agrícolas trazidas de seus lugares de origem.

Os primeiros imigrantes não tiveram uma vida muito tranquila, pois sua principal atividade de trabalho era a agricultura, muitas vezes instável em função do clima e das intempéries. Desta atividade, os colonos tiravam os produtos para a subsistência e o excedente para abastecer o mercado das metrópoles da época.

O grande salto no desenvolvimento de Gramado veio com a inauguração da estrada de ferro, em 1924, que ligava Porto Alegre a Gramado. A chegada da estação ferroviária e da linha férrea à região teve um grande impacto nas relações econômicas, pois aquele meio de transporte passou a fazer ligação de modo mais rápido entre Gramado e as principais cidades da região naquele período. Com esta grande mudança, a atividade econômica começou a se transformar, surgindo um comércio mais diversificado, e proporcionando a chegada de professores, médicos, dentre outros profissionais que antes possuíam como forma de chegar a esta localidade o transporte das mulas.

Foi em 1918 que surgiu o primeiro serviço de hospedagem de Gramado, com o Hotel Bertolucci. Porém, somente no ano de 1930, depois de concluído o processo de colonização de origem europeia, Gramado passa a ganhar forma e tamanho de uma cidade turística, devido, principalmente, a suas belezas naturais. Os primeiros visitantes de Gramado eram chamados de veranistas, pois visitavam Gramado nos meses de verão, entre dezembro e fevereiro, buscando as temperaturas mais amenas. Estes vinham principalmente da região metropolitana de Porto Alegre e seus arredores. Os principais atrativos naturais da época eram as cascatas do Véu de Noiva e Cascata do Narciso ${ }^{1}$. Nesse período, os turistas não vinham para Gramado no período de inverno devido à falta de estrutura local.

Esse período foi muito próspero para Gramado, período em que a localidade passa a se firmar como cidade turística do Rio Grande do Sul. Geralmente as pessoas que moravam na capital tinham Gramado como lugar de descanso principalmente nos finais de semana, além de servir como "colônia de férias" para os metropolitanos.

\footnotetext{
${ }^{1}$ Narciso é escrita no singular, pois se refere à família Narciso, que possuía terras aos arredores da cascata, não se relacionando a flor narciso.
} 


\section{O desenvolvimento de Gramado através do turismo e das festas}

Podemos conceituar o Patrimônio Cultural como um conjunto de bens de natureza material e imaterial que, por sua vez, são considerados coletivos e preservados durante o tempo. Segundo Maia, o Patrimônio Cultural é expresso pela Constituição Federal de 1988, que o define no artigo 216: "Constituem patrimônio cultural brasileiro os bens de natureza material e imaterial, tomados individualmente ou em conjunto, portadores de referência à identidade, à ação, à memória dos diferentes grupos formadores da sociedade brasileira." (MAIA, 2003, p. 39).

O Patrimônio Cultural comporta, ainda, os diferentes costumes de viver de um povo, transmitidos de geração a geração e recebidos por tradição. Esses, para se tornarem um Patrimônio, precisam ser reconhecidos e compartilhados pela comunidade que os produzem, como é o caso encontrado em Gramado. Como já afirmamos, o Patrimônio Cultural é dividido em duas categorias: os bens materiais e os bens imateriais. Segundo Feitosa e Silva (2011), os bens imateriais são todos aqueles relacionados à memória e identidades e heranças de um povo ou nação, enquanto o patrimônio cultural material é todo aquele que pode ser visto e tocado.

De acordo com a UNESCO (2002), os bens imateriais são definidos como práticas, expressões, técnicas e conhecimentos que são transmitidos de geração em geração e são constantemente recriados pelas comunidades, que os reconhecem como parte integrante de seu grupo. Já para Rodrigues (2006), o patrimônio cultural é um conjunto de bens materiais e imateriais que são de interesse do coletivo perpetuados durante o tempo. Estes têm a função de relembrar acontecimentos tidos como importantes na memória social.

Já para Tomaz (2010), o patrimônio deve ir além de mera concepção de bens materiais e imateriais, pois deve ser entendido como um processo social formado através da dinâmica das experiências coletivas, com o qual a coletividade preserva e transforma com o tempo.

Também Choay (2006, p. 11) apresenta uma clara definição sobre o patrimônio, que pode ser compreendido como "um bem destinado ao usufruto de uma comunidade que se ampliou a dimensões planetárias, constituído pela acumulação contínua de uma diversidade de objetos que se congregam por seu passado comum". Por seu turno, Tomaz (2010) afirma que a preservação do patrimônio cultural consiste em conservar traços históricos de uma sociedade. Desta forma, podemos considerar o patrimônio cultural, seja material ou imaterial, como fruto da identidade de um povo. Este representa tudo o que deve ser preservado, ou seja, tudo o que não deve ser esquecido, ainda que, na maioria das vezes, atendendo aos interesses de determinados grupos que o manipulam. 
Associado a essa questão patrimonial, a identidade de um grupo pode ser compreendida como aquilo que diferencia o homem a partir de suas ações e marca de modo mais especial o passado. Com a Constituição Federal de 1988 foi possível dar visibilidade ao patrimônio, dando reconhecimento a bens culturais e naturais, assim como deu legitimidade a preservação, presentes nos artigos 215 e 216 da Constituição Federal e já em 1937 com a instituição do Decreto de Lei nº 25, de 30/11/1937, que trata do Tombamento e é adequado, principalmente, à proteção de edificações, paisagens e conjuntos históricos urbanos.

O Instituto do Patrimônio Histórico e Artístico Nacional - IPHAN define que os Bens Culturais de Natureza Imaterial dizem respeito àquelas práticas e domínios da vida social que se manifestam em saberes, ofícios e modos de fazer, bem como em celebrações, formas de expressão cênicas, plásticas, musicais ou lúdicas e ainda em lugares como mercados, feiras e santuários que abrigam práticas culturais coletivas.

O Patrimônio Cultural Imaterial, de acordo com o IPHAN, é transmitido de geração a geração, constantemente recriado pelas comunidades e grupos em função de seu ambiente, de sua interação com a natureza e de sua história, gerando um sentimento de identidade e continuidade, contribuindo para promover o respeito à diversidade cultural e à criatividade humana. É apropriado por indivíduos e grupos sociais como importante elemento de sua identidade.

Nesse sentido, os eventos populares - como é o caso do Natal Luz de Gramado podem ser abordados como uma categoria pertencente ao campo do patrimônio cultural imaterial, englobando saberes, lugares e modos de fazer, que comunicam algo sobre a identidade de um povo, transmitidos de geração em geração. Com isso, percebemos que os hábitos e as tradições de um povo nos dizem e revelam parte da sua cultura. Ainda, para Veloso (2006), o conceito de referência cultural ressalta o processo de produção e reprodução de um determinado grupo social e aponta para a existência de um universo simbólico compartilhado.

Nesse contexto de discussão, entendemos que os eventos promovidos por uma comunidade podem ser de caráter popular, religioso, cultural e social e geralmente retratam recortes do cotidiano e trajetórias históricas dos grupos que os produzem. Esses recortes, como uma festa que faz referência ao Natal, podem ser entendidos como um processo que busca retratar aspectos da vida cotidiana da comunidade e que, a partir da promoção da festa, passam a representar elementos simbólicos da coletividade, ao mesmo tempo em que buscam a promoção do desenvolvimento econômico da comunidade, através da atração de turistas para suas festividades.

$\mathrm{Na}$ perspectiva apresentada pelo IPHAN, os eventos são atos humanos que se transformam em ato social e cultural. Podemos compreendê-lo como um sistema simbólico, que atua como vetor de comunicação, nos permitindo a compreensão da sociedade em que se está inserido. Dessa forma, as festas e os eventos 
populares retratam o cotidiano - ou parte dele - de um povo, e são criados de acordo com um processo histórico, articulando elementos tradicionais, com o objetivo de criar algo único, que se torna particular, singular e reconhecível por aqueles que "olham de fora".

Com o recente crescimento do Turismo, as festas e eventos populares têm se tornado os principais atrativos turísticos e, segundo Arantes (2004), as celebrações populares tem permitido um aporte financeiro para as comunidades locais que as produzem. Com isso, os eventos populares - como é nosso caso - têm a capacidade de comunicar aspectos identitários, geográficos, históricos e culturais da comunidade.

Mesmo com a potencialidade financeira dada às comunidades a partir das festas e eventos que valorizam ou se constituem a partir do patrimônio, Veloso (2006) faz um contraponto sobre o papel desempenhado pelo Patrimônio Cultural na sociedade contemporânea. Para ela, houve uma intensa ação de comercialização da cultura, com incremento ao consumo da cultura de forma maciça. Ainda segundo a autora, se "[...], permitiu o acesso mais igualitário aos equipamentos culturais por parte de diferentes grupos sociais e, por outro lado, maquiou, ou pelo menos simplificou ou banalizou as manifestações culturais com o verniz do consumo." (VELOSO, 2006, p. 445).

A mesma autora alerta ainda para o perigo de transformar o Patrimônio Cultural Imaterial apenas pelas suas formas objetivadas em objetos ou produtos de consumo visando exclusivamente o lucro. Em seu entendimento, "sempre que as manifestações do patrimônio imaterial se transformam em mercadorias, em entretenimento para o consumo, em espetacularização, a ênfase é posta no fetiche." (VELOSO, 2006, p. 445). Sendo assim, na perspectiva apresentada pela autora, se desfazem as relações sociais dos indivíduos produtores da cultura e do patrimônio, e se exaltam as relações entre as mercadorias e as coisas. Ainda de acordo com Veloso, para que não se perca o sentido de determinada manifestação cultural produzida pelos grupos, faz-se necessário distanciar-se da coisificação e espetacularização do Patrimônio.

Com a globalização e o crescimento da indústria mundial do Turismo, há, muitas vezes, uma tendência em transformar o Patrimônio Cultural Imaterial em produtos de consumo. Isto fica claro nos grandes festejos populares do Brasil, que atualmente são muito utilizados para incrementar a atividade turística local.

O autor ainda chama a atenção para observação sobre o poder econômico e político relacionados a conglomerados de empresas que projetam o Turismo com vinculação ao patrimônio. A partir do uso do Patrimônio como forma de estimular a economia, potencializa-se a criação de um cenário artificial a partir desta mercantilização. Com o passar dos anos, o Turismo pode tornar-se apenas um comércio, isso porque os comerciantes utilizam-se dos espaços no entorno dos patrimônios utilizados para atração turística e passam a visualizar estes 
patrimônios apenas como forma de obtenção de lucros, hostilizando até mesmo a relação com o turista.

Oliveira (2008) destaca que a criação de um cenário de cultura artificial, num primeiro momento faz com que os turistas sejam recebidos com euforia. Depois, entretanto, as relações vão se esvaziando, tornando estas relações apenas comerciais, onde existe uma maior necessidade de atender de forma mais completa este turista e fazendo com que o prestador de serviço fique apático às atividades que potencializam o seu negócio, sendo estas a cultura e o patrimônio.

Quando o fluxo de turistas aumenta ainda mais gerando mudanças na localidade, como preços elevados, podem exercer limites de tolerância e sabotagem por parte da comunidade, causando irritação e conflitos entre os diferentes grupos sociais atingidos pelas mudanças.

Portanto, quando se fala em Patrimônio Cultural, tanto material quanto imaterial, é preciso entender que este é fruto de relações sociais e da evolução de uma comunidade no processo histórico. Contudo, o patrimônio cultural não pode correr o risco de tornar-se apenas um objeto de consumo visando apenas o lucro, pois quando isto acontece começa a perder os valores coletivos.

Nesse contexto de discussão é que temos, em meados de 1950, significativas transformações econômicas e sociais em Gramado. A atividade de veraneio na Serra sofre uma redução sensível. São dois os motivos fundamentais que levaram a redução de visitantes a Gramado. O primeiro foi o surgimento do veraneio no litoral, quando nascem balneários turísticos junto ao litoral Gaúcho. O segundo foi o processo iniciado pelo Governo Federal de troca da matriz de transporte ferroviário para a matriz de transporte rodoviário, que provocou e desativação da estrada de ferro que ligava Gramado à capital do estado.

No ano de 1954, Gramado obtém sua emancipação política, e a partir daí a cidade responde à crise criada no período anterior, iniciando seu processo de desenvolvimento econômico. O período é marco para o processo de consolidação de uma cidade turística: os primeiros administradores, com objetivo de aumentar o número de turistas nos meses de verão, criaram, em 1958, a Festa das Hortênsias.

Acessando o Gramado Site, encontramos informações relevantes sobre a Festa das Hortênsias. Nele, Daros (2012) afirma que "quando a festa das Hortênsias nasceu, em 07 de dezembro de 1958, Gramado despontava para o turismo de eventos e foi com esta festa que os gramadenses aprenderam tudo que sabem". Para a pesquisadora, a Festa das Hortênsias foi a precursora de todos os eventos em Gramado.

A Festa das Hortênsias foi inspirada nas plantações dessa espécie que cobriam a entrada da cidade e tinha como objetivo trazer os veranistas nos meses de dezembro a fevereiro. Entretanto, essa festa acabou sendo o marco precursor da cidade para o turismo de eventos. 
A partir desse evento, segundo Daros (2012), Gramado ficou conhecida nacionalmente, e desde então o turismo local tem se direcionado para uma constante produção de eventos a fim de conseguir atrair grande número de turistas que, cada vez mais, tornam-se indispensáveis para manter a organização turística que se estruturou na cidade. Podemos destacar que se este surgiu em um momento de crise e se tornou indispensável para manter a organização turística, também deve ser considerado indispensável para a manutenção do desenvolvimento e é um fator condicionante do crescimento de Gramado.

Através do tempo, Gramado conseguiu acompanhar as mudanças e as tendências do Turismo. Por meio do empreendedorismo, conseguiu aliar as belezas naturais a um espírito inovador, e desenvolveu uma das melhores estruturas de eventos do Brasil. A cidade deu dinamicidade a sua estrutura a partir da Festa das Hortênsias, quando também foram criados os principais eventos que Gramado tem na atualidade: o Natal Luz e o Festival de Cinema.

Vale ressaltar que o Natal Luz nasceu na $12^{\mathrm{a}}$ edição da Festa das Hortênsias, em 1986, ano em que 500 cantores e 20 papais noeis saíram em torno do Lago Joaquina Rita Bier cantando músicas natalinas, e, na noite de 27 de dezembro, reuniram-se na praça Major Nicolleti mais de cinco mil pessoas.

A Festa das Hortênsias foi se reinventando através dos anos e articulando novos eventos, com o objetivo principal de atrair turistas e promover a cidade nos meses de verão. Porém, a festa teve seu término em 1987, na sua $12^{a}$ edição. Naquele mesmo ano se iniciou o $1^{\circ}$ Natal Luz de Gramado.

\section{O Natal Luz e os eventos na cidade}

O Natal Luz é o maior evento natalino do Brasil e também o principal evento da cidade de Gramado. O evento Natal Luz chegou a sua $28^{a}$ edição no ano de 2013, sendo o principal responsável por aquecer a economia local nos meses de novembro a janeiro. Tendo sido criado dentro da $12^{\circ}$ Festa das Hortênsias, podemos afirmar que a festividade nasceu como uma festa popular. $\mathrm{Na}$ ocasião, vários corais organizados por diferentes grupos e também de congregações religiosas da cidade, com a participação da comunidade, saíram pela Avenida Borges de Medeiros $^{2}$, com velas acesas nas mãos e entoando cânticos de Natal,

\footnotetext{
${ }^{2}$ Principal avenida de Gramado, que corta todo o centro da cidade, ligando-o aos principais bairros da cidade. Trata-se de uma avenida que recebe cuidados especiais por parte da administração pública municipal. É reconhecida como uma via muito bem cuidada e que recebe tratamento paisagístico especial, como o plantio de flores, vasos e luminárias estilizadas com vasos de flores pendentes. Durante o Natal Luz fica repleta de objetos de decoração natalina.
} 
num espetáculo com muita luz, animação e participação da comunidade local como um todo.

Nas primeiras edições observava-se uma participação mais afetiva dos moradores - de diferentes segmentos da sociedade local -, que se envolveram diretamente na criação da programação, nas atrações e até mesmo na confecção da decoração natalina. Nesse caso, a prefeitura municipal entrava apenas como apoiadora do evento, sendo a responsabilidade de execução e gestão dos custos da própria comissão comunitária, que era a única responsável.

Essa realidade contrasta com a atual, em que o Natal Luz é planejado, promovido, executado e administrado pela 'Gramado Tur', uma autarquia da Prefeitura Municipal de Gramado. Atualmente, todas as compras e a contratação de serviços para o Natal Luz são feitas através de licitação. Então se conclui que o evento não é mais da comunidade, uma vez que é administrado por um órgão específico. Vale ressaltar ainda que esta autarquia, ligada ao poder público local, foi criada em razão da antiga empresa que promovia o evento Natal Luz ter tido problemas com corrupção e desvio de verbas, levando o caso para a mídia regional, na qual foram veiculadas notícias envolvendo os responsáveis da empresa e o superfaturamento dos gastos.

Dessa forma, atualmente o evento conta - de forma sensível - com menor envolvimento da população em sua organização e tomada de decisões, especialmente no que se refere aos espetáculos, organização e ornamentação da cidade. A profissionalização e a burocratização do evento fizeram com que a execução das festividades se tornasse algo cada vez mais distante da comunidade, a propulsora do evento em seu início. No mesmo sentido, observamos o aumento expressivo dos valores gastos com a preparação das festividades, o que demonstra a preocupação cada vez maior dos seus organizadores - que passam a sofrer as pressões dos empresários locais - com a glamorização da festa, que atrai todos os anos um número crescente de turistas.

É importante observar ainda alguns aspectos que nos permitem avaliar como o Natal Luz tem passado, nos últimos anos, por um processo de aperfeiçoamento técnico. Em 2010 foi criado pela prefeitura municipal a Escola das Artes Pedro Henrique Benetti do Natal Luz de Gramado. Naquele ano, cerca de 140 pessoas, entre crianças, jovens e adultos, receberam de forma gratuita, formação artística, sendo que a grande maioria foi contratada para integrar as equipes das grandes atrações do Natal Luz.

Outro exemplo pode ser visto na divulgação feita na cidade sobre a seleção dos novos talentos que constituirão as equipes de apresentação para a edição do $29^{\circ}$ Natal Luz que será realizado de 30 de outubro de 2014 a 11 de janeiro de 2015. De acordo com a divulgação, serão selecionados os 23 integrantes da Parada de Natal e os 392 personagens do Grande Desfile de Natal. 
Ainda que parte da população de Gramado esteja envolvida com a execução do evento, notamos uma valorização significativa de apresentações artísticas e personalidades que são trazidas de fora da cidade. As próprias empresas contratadas para executar serviços técnicos e de suporte não são da cidade. Com isso, ao mesmo tempo em que o evento se aperfeiçoa em termos técnicos - o que também é valido e necessário - ele acaba tomando feições cada vez mais artificiais, na medida em que os organizadores passam a contratar pessoas e serviços que não envolvem o trabalho comunitário, como ocorria nos primeiros tempos do evento.

Por outro lado, o evento Natal Luz envolve atualmente a comunidade de modo mais direto no desenvolvimento de novos serviços e estruturas de atendimento ao turista, que vem sempre em busca de novos atrativos, o que possibilita a contratação de mais mão de obra e a geração de renda local. Dessa forma, a população antes envolvida diretamente com a execução do evento passa a desempenhar um papel coadjuvante na organização, numa perspectiva "de suporte" das diferentes atividades econômicas desenvolvidas na cidade.

O evento trabalha ainda na promoção do desenvolvimento da sociedade local, contribuindo para a sustentabilidade ambiental, uma vez que a cidade é em sua maioria decorada com materiais reciclados que são arrecadados junto às escolas e transformados em decoração. Desde 2010 o evento foi acrescido de uma característica social, sendo que, segundo dados do site do Natal Luz, o evento arrecadou somente na edição de 2011 mais de 15 toneladas de alimentos que foram doados às entidades do município.

$\mathrm{Na}$ sua $28^{a}$ edição, o Natal Luz de Gramado 2013/2014 levou aos turistas e população local mais de 500 atrações em 73 dias de duração. O evento, que iniciou com uma caminhada iluminada e vozes entoando cantos natalinos pela cidade, tem ganhado a cada ano um número maior de atrações.

Observamos ainda que o evento passa a ser preparado com forte apelo comercial, com a melhoria e o incremento de atrações, oferecimento de novos serviços, além dos espaços e materiais de divulgação, como podemos observar na Tabela 2, apresentada abaixo: 
Tabela 2 - Atrações Natal Luz 2013/2014

\begin{tabular}{cl}
\hline$N^{\text {o }}$ & \multicolumn{1}{c}{ Atrações do Natal Luz 2013/2014 } \\
\hline 1 & Corrida e Caminhada de Noel \\
3 & Gativitaten \\
4 & Frande Desfile de Natal \\
5 & Natalica Fábrica de Natal \\
6 & Árvore Cantante \\
7 & Au Au, Uma Aventura de Natal \\
8 & Concertos de Natal \\
9 & Corais \\
10 & Exposição de Renas Decoradas \\
11 & Folia dos Reis \\
12 & Fritz: o chapéu do Papai Noel \\
13 & Happy Hour Christmas \\
14 & Natal no Sul \\
15 & Parada de Natal \\
16 & Quinteto de Natal \\
17 & Rua dos Quebra-Nozes \\
18 & Show de Acendimento \\
19 & Tannenbaumfest \\
20 & Teatro de Bonecos \\
21 & Vila de Natal \\
\hline
\end{tabular}

Fonte: Natal Luz de Gramado (GRAMADO, 2014a).

A partir de dados referentes à evolução das atrações do evento no Gramado Site, apresentamos uma tabela com a série histórica de 1990 a 2013 das atrações que foram sendo agregadas à programação do Natal Luz. A Tabela 3, por sua vez, mostra que foram criadas atrações no período, sendo essa uma evidência que nos permite afirmar que o evento se transformou, progressivamente, numa forma de comércio lucrativo. 
Tabela 3 - Atrações criadas de 1990-2013

\begin{tabular}{|c|c|}
\hline Ano & Atrações criadas \\
\hline $1990-1992$ & Corais \\
\hline \multirow{3}{*}{1993} & $\begin{array}{l}\text { Apresentação de corais e } 3 \text { pianistas em } \\
\text { balsas no Lago Joaquina Rita Bier }\end{array}$ \\
\hline & Chegada do Papai Noel \\
\hline & Árvore Cantante \\
\hline $1997-2000$ & 2 grandes Concertos \\
\hline \multirow{2}{*}{2001} & Grande Desfile de Natal \\
\hline & Nativitaten \\
\hline $2003-2005$ & Natal no Sul \\
\hline 2006 & Fantástica Fábrica de Natal \\
\hline 2007 & Tributo ao maestro Eleazar de Carvalho \\
\hline 2008 & A encantadora Arca de Noel \\
\hline 2009 & Povo da Vila de Natal \\
\hline 2010 & \\
\hline 2011 & \\
\hline 2011 & \\
\hline 2013 & \\
\hline 2013 & Natalis \\
\hline
\end{tabular}

Fonte: Natal Luz de Gramado (GRAMADO, 2014a).

Buscando melhor compreender o processo de transformação da economia local promovido pelo Natal Luz, elaboramos o Gráfico 1, no qual constatamos que em 2003 o evento atraiu para a cidade 453.649 turistas, sendo que em 2013 o evento passou a contar com um público de 1.482.665.

Esses números deixam claro que o evento teve um enorme crescimento. Nos últimos dez anos, o Natal Luz teve uma evolução no número de turistas em torno de $227 \%$. Quando se faz uma análise comparativa da evolução de atrações com o número de turistas, pode-se perceber a evidência de que este Patrimônio Cultural está transformando, ainda que talvez de forma não proposital, em uma mercadoria que visa o lucro econômico. 


\section{Gráfico 1 - Evolução de Turistas do Natal Luz de Gramado, 2003-2013}



Fonte: Secretaria do Turismo de Gramado (GRAMADO, 2014b).

A cada ano, o evento conta com significativo aumento no fluxo de turistas, sendo que, nos últimos três anos, ele está superando a temporada de inverno. Segundo a 'Gramado Tur', o evento está gerando melhores oportunidades de negócios para lojas, hotéis e restaurantes. Neste sentido, para atender as necessidades econômicas locais e atender as demandas de turistas, o evento torne-se, de certa forma, artificial, perdendo suas características originais de envolvimento da comunidade e de participação da população local nas atrações programadas, pois tudo torna-se relação de comércio, perdendo a relação de proximidade entre a comunidade e seus visitantes.

Segundo Oliveira (2008), quando isto acontece inicia-se um processo no qual se perdem os valores coletivos identitários da comunidade local. $\mathrm{O}$ autor completa dizendo que os residentes ficam apáticos à atividade como forma de apenas se obter lucro. A cidade, nesse contexto, transforma-se num grande palco, onde a teatralização do cotidiano transforma seus moradores em simples personagens que passam a viver em função do servir.

Seguindo nossa análise, apresentamos o Gráfico 2, que aponta a comparação entre o mês de julho e dezembro dos anos de 2010 a 2012. O gráfico mostra que o evento Natal Luz alavancou fluxos de turistas no mês dezembro na cidade de Gramado. Esta amostra evidencia que o evento tornou-se um objeto e espaço de consumo, perdendo, em grande parte, seus valores culturais originais que remetiam aos valores culturais, considerados parte do patrimônio cultural da comunidade gramadense. 
Nesse sentido, os elementos que originalmente eram potencializados, como a culinária dos moradores da zona rural, o artesanato local e a simplicidade da vida de seus moradores mais antigos, passam a ser secundários. Em seu lugar, são colocados a sofisticação dos restaurantes de culinária internacional, o requinte dos hotéis e a glamorização das atividades culturais e artísticas voltadas para os turistas, dispostos a gastar quantias significativas em sua estadia na cidade na época que antecede o Natal.

Gráfico 2 - Ocupação da Hotelaria, 2010-2012



Fonte: Gramatur, Natal Luz (2014).

Segundo o Portal de Notícias G1, no período de 20 a 29 de dezembro de 2013, a projeção de ocupação era de $95 \%$ dos leitos da cidade de Gramado, sendo uma das alternativas, pequenas pousadas e hotéis de menor porte nas cidades vizinhas, como Nova Petrópolis e São Francisco de Paula. Ou seja, efetivamente, o evento Natal Luz produz efeitos positivos na comunidade, uma vez que provoca aumento das atividades econômicas e, com isso, maior oferta de trabalho e geração de renda no município.

Dessa forma, o comércio e todas as demais atividades associadas à presença do turista na cidade acabam ganhando, na medida em que quantias significativas são trazidas por esses turistas na cidade, especialmente na época de Natal. 


\section{Considerações finais}

O evento Natal Luz está se reinventando através dos anos e articulando novos eventos em sua programação, com o objetivo principal de atrair turistas e promover a cidade nos meses de verão. O Natal Luz é o maior evento natalino do Brasil e se consolida como o principal evento da cidade de Gramado. O evento chegou a sua $28^{a}$ edição em 2013, sendo o principal responsável por aquecer a economia local nos meses de novembro a janeiro.

Ao longo de sua trajetória, o evento veio se ressignificando e conquistou seu reconhecimento como Patrimônio Cultural do Rio Grande do Sul. Sua importância, no sentido de contribuir para o desenvolvimento econômico de Gramado, é inquestionável, embora o desenvolvimento das atividades da própria dinâmica do evento o tivessem descaracterizado enquanto Patrimônio Cultural da comunidade gramadense.

Nessa perspectiva analisada, compreendemos que o evento tem se tornado um produto de consumo e, com isto, uma alternativa de patrimonialização pessimista (FEITOSA; SILVA, 2011). Afirmamos isso uma vez que o evento se tornou, em nosso entendimento, uma mercadoria de consumo, desconsiderando suas contribuições históricas e culturais, as quais inicialmente orientavam a organização do evento na cidade.

A sofisticação e glamorização do evento fizeram com que os elementos simbólicos que remetiam à memória e a identidade da comunidade se perdessem no tempo, ou, talvez, passassem por um processo de (re)atualização, perdendo suas características originais. Daí ser possível falar de um bibridismo cultural presente no Natal Luz de Gramado nos dias atuais.

Também se buscou, através desta pesquisa, uma compreensão mais profunda sobre o evento e de como este ato social transformou-se em cultura, assim como perceber como esse evento articula-se com os símbolos e pensamentos idealizados sobre a comunidade, uma vez que o evento Natal Luz procura retratar o cotidiano da população gramadense e seus aspectos históricos e religiosos. Porém, de acordo com a análise feita, consideramos que o mesmo se transformou essencialmente em espaço de consumo.

Nesse contexto, cabe ampliar as discussões no âmbito acadêmico sobre como conciliar os avanços econômicos com a preservação da memória e da identidade da comunidade de Gramado. Vale ainda analisar de que modo estes espaços contribuem para elucidar o que não deve ser esquecido em um evento que a cada ano (re)inventa alegorias e coisifica elementos culturais para atrair novas possibilidades de desenvolvimento regional. 


\section{Referências}

ARANTES, Antonio A. Patrimônio imaterial e a sustentabilidade de sua salvaguarda. Resgate, v. 8, n. 1, p. 11-18, 2004.

BARROS, José D’Assunção. Cidade e História. Petrópolis: Vozes, 2007.

CANDAU, Jöel. Memória e identidade. São Paulo: Contexto, 2012.

CHOAY, Françoise. A alegoria do patrimônio. 3 ed. São Paulo: Unesp, 2006.

DAROS, Marília. Colonização: As etnias formativas de Gramado. Gramado Site. Disponível em <http://gramadosite.com.br/cgi/cultura/mariliadaros/id: 26870/imprimir:1>. Acesso em: 20 fev. 2012.

FEITOSA, Mônica Nascimento; SILVA, Sandra Siqueira da. Patrimônio Cultural imaterial e políticas públicas: os saberes da culinária regional como fator de desenvolvimento local. Salvador: UFBA, p. 193-208, 2011.

FEE. Fundação de Economia e Estatística do Rio Grande do Sul. População. Disponível em: <www.fee.tche.br> Acesso em: 1 abr. 2013.

GRAMADO. Prefeitura Municipal de. Natal Luz de Gramado. Disponível em $<$ www.gramado.rs.gov.br>. Acesso em 30 mai. 2014a.

. Secretaria de Turismo de. Tabela de Eventos e Evolução de turista de

2003 a 2013. [mensagem pessoal] Mensagem recebida por: <turismo@gramado.rs.gov.br> em 2 mar.2014b.

GRAMATUR. Natal Luz Gramado Arte que celebra a vida. Relatório de Atividade 2013. Gramado: Printpaper, 2013. 23 p. (1). Relatoria de Atividade do $27^{\circ}$ Natal Luz.

HALBWACHS, Maurice. A memória coletiva. São Paulo: Centauro, 2004.

HALL, Stuart. Quem precisa da identidade? In: SILVA, Tomaz Tadeu da (Org.). Identidade e diferença: a perspectiva dos Estudos Culturais. 14 ed. Petrópolis: Vozes, 2014. p. 103-133.

MAIA, Felícia Assmar. Direito à memória: o patrimônio histórico, artístico e cultural e o poder econômico. Movendo idéias, Belém, v. 8, n. 13, p. 39-42, jun. 2003. 
MUMFORD, Lewis. A cidade na história: suas origens, transformações e perspectivas. São Paulo: Martins Fontes, 1998.

OLIVEIRA, Hélida Vilela. A prática do turismo como fator de inclusão social. Anhanguera Educacional S.A. Revista de Ciências Gerenciais, v. XII, n. 16, p. 91-103, 2008.

POUTIGNAT, Philippe; STREITFF-FENART, Jocelyne. Teorias da etnicidade seguido de Grupos étnicos e suas fronteiras de Frederik Barth. São Paulo: Editora da UNESP, 1998.

RODRIGUES, Cíntia Nigro. Territórios do patrimônio: tombamentos e participação social na cidade de São Paulo. 256 f. Dissertação (Mestrado em Geografia), Departamento de Geografia, USP, São Paulo, 2006.

SILVA, Tomaz Tadeu da. A produção social da identidade e da diferença. In: SILVA, Tomaz Tadeu da (Org.). Identidade e diferença: a perspectiva dos Estudos Culturais. 14 ed. Petrópolis: Vozes, 2014. p. 73-102.

TOMAZ, Paulo Cesar. A preservação do patrimônio cultural e sua trajetória no Brasil. Revista de História e Estudo Culturais, São Paulo, v. 7, n. 2, p. 1-12, maio/ago. 2010.

UNESCO. Organização das Nações Unidas para a Educação, Ciência e Cultura. Bens imateriais. In: II Congresso Nacional sobre Investimento Social Privado Educação, Diversidade Criadora e Cultura de Paz. Fortaleza: UNESCO, 2002. Anais... Disponível em: <http://www.brasilia.unesco.org/noticias/opiniao/ index/index_2002/gife> Acesso em: 25 abr. 2014.

VELOSO, Mariza. O Fetiche do Patrimônio. Revista Habitus, Goiânia, v. 4, n. 1, jan./jun. p. 437-454, 2006.

WOODWARD, Kathryn. Identidade e diferença: uma introdução teórica e conceitual. In: SILVA, Tomaz Tadeu da (Org). Identidade e diferença: a perspectiva dos Estudos Culturais. 14 ed. Petrópolis: Vozes, 2014. p. 7-72. 
Endereço para correspondência:

DanielLucianoGevehr - danielgevehr@hotmail.com Av. Oscar Martins Rangel, 4500

95600-000 Taquara/RS, Brasil

RogerPierreVidal-rogerpvidal@hotmail.com

Av. Oscar Martins Rangel, 4500

95600-000 Taquara/RS, Brasil

Aline Nandi - alinen_sintraf@hotmail.com

Av. Oscar Martins Rangel, 4500

95600-000 Taquara/RS, Brasil 